\title{
Caffeine Intoxication Successfully Treated by Hemoperfusion and Hemodialysis
}

\author{
Sayaka Ishigaki ${ }^{1}$, Hirotaka Fukasawa ${ }^{1}$, Naoko Kinoshita-Katahashi ${ }^{1}$, Hideo Yasuda ${ }^{2}$, \\ Hiromichi Kumagai ${ }^{3}$ and Ryuichi Furuya ${ }^{1}$
}

\begin{abstract}
Caffeine is an easily available drug which is generally regarded as being safe. However, it can lead to a lethal outcome in severe cases of caffeine intoxication. We herein report a case of a 32-year-old man who ingested approximately $15.6 \mathrm{~g}$ of caffeine in a suicide attempt. He suffered from sustained ventricular tachycardia despite conservative treatment. Therefore, we performed a combined therapy of hemoperfusion and hemodialysis which resulted in rapid improvement of the patient's ventricular tachycardia as well as a reduction of the patient's plasma caffeine level. To the best of our knowledge, this combination has not been previously reported to treat caffeine intoxication.
\end{abstract}

Key words: caffeine intoxication, hemoperfusion, hemodialysis

(Intern Med 53: 2745-2747, 2014)

(DOI: 10.2169/internalmedicine.53.2882)

\section{Introduction}

Caffeine is available in a wide variety of over-the-counter formulations, such as diet aids and combination analgesics, although a caffeine overdose can lead to life-threatening complications, such as seizures and cardiac arrhythmias $(1,2)$.

We herein report the case of a 32-year-old man who survived despite severe cardiac complications due to caffeine intoxication. Our case suggests that the combination of hemoperfusion and hemodialysis is beneficial for patients with lethal caffeine intoxication.

\section{Case Report}

A 32-year-old man with a six-year history of schizophrenia was transferred to the emergency department of our hospital. According to his description, he ingested 156 tablets containing approximately $15.6 \mathrm{~g}$ of caffeine in a suicide attempt.

On arrival, his Glasgow Coma Scale was 14 (E4V4M6), his blood pressure was $114 / 61 \mathrm{mmHg}$, and electrocardio- gram showed sinus tachycardia at a rate of 116 beats/min. An arterial blood gas analysis showed mild metabolic acidosis (bicarbonate, $18.3 \mathrm{mmol} / \mathrm{L}$ ). The other laboratory data were as follows: white blood cells, $10,100 / \mu \mathrm{L}$; red blood cells, $536 \times 10^{4} / \mu \mathrm{L}$; hemoglobin, $16.0 \mathrm{~g} / \mathrm{dL}$; platelets, $25.4 \times$ $104 / \mu \mathrm{L}$; serum creatine kinase, $116 \mathrm{IU} / \mathrm{L}$; blood urea nitrogen, $12 \mathrm{mg} / \mathrm{dL}$ (4.3 mmol/L); serum creatinine, $0.95 \mathrm{mg} / \mathrm{dL}$ (84.0 $\mu \mathrm{mol} / \mathrm{L}$ ); sodium, $140 \mathrm{mmol} / \mathrm{L}$; potassium, $2.7 \mathrm{mmol} /$ $\mathrm{L}$; chloride, $101 \mathrm{mmol} / \mathrm{L}$; and blood glucose, $176 \mathrm{mg} / \mathrm{dL}$ (9.8 mmol/L). Approximately 0.5 hours after arrival (2 hours after ingestion), he suddenly developed a tonic-clonic seizure, which was alleviated with diazepam, although the patient required an additional intravenous drip infusion of midazolam to control recurrent seizures. Furthermore, one hour after arrival (2.5 hours after ingestion), he developed ventricular tachycardia (but not pulseless); therefore, we intravenously administered $100 \mathrm{mg}$ of lidocaine and $2 \mathrm{~g}$ of magnesium sulfate. However, his ventricular tachycardia persisted (Fig. 1A). Because of this lethal cardiac complication, we decided to carry out blood purification therapy combined with hemoperfusion and hemodialysis to eliminate the excessive blood caffeine.

Hemoperfusion with a charcoal cartridge $\left(\mathrm{DHP}-1^{\circledR}\right.$,

${ }^{1}$ Renal Division, Department of Internal Medicine, Iwata City Hospital, Japan, ${ }^{2}$ First Department of Medicine, Hamamatsu University School of Medicine, Japan and ${ }^{3}$ The Department of Clinical Nutrition, School of Food and Nutritional Sciences, University of Shizuoka, Japan Received for publication March 14, 2014; Accepted for publication May 20, 2014

Correspondence to Dr. Sayaka Ishigaki, sayakahonda@hotmail.co.jp 
(A)

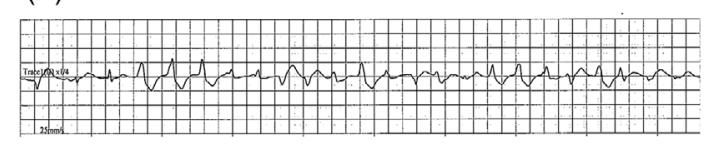

(B)

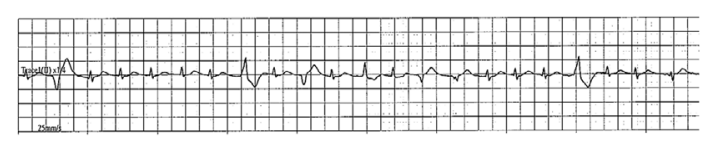

(C)

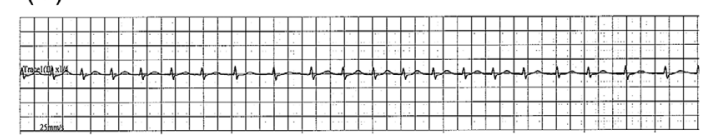

Figure 1. Electrocardiogram findings at the start of and during the blood purification therapy. The images shown are (A) at the start of the treatment, $(\mathrm{B}) \mathbf{0 . 5}$ hours after the start of treatment, and (C) 2 hours after the start of treatment.

Kawasumi Laboratories, Tokyo, Japan) and hemodialysis with a cellulose triacetate dialyser (FB-70G eco ${ }^{\circledR}$, Nipro, Osaka, Japan) were initiated 4 hours after caffeine ingestion. These columns were connected in tandem and then carried out simultaneously. The blood and dialysate flow rates held steady at 150 and $500 \mathrm{~mL} / \mathrm{min}$, respectively. His initial caffeine level was $237 \mathrm{mg} / \mathrm{L}$ (Fig. 2). After the beginning of the blood purification therapy, his ventricular tachycardia improved within 0.5 hours, and his ventricular arrhythmia completely disappeared within 2 hours (Fig. 1B and C, respectively). The therapy lasted for a total of 3 hours. We observed no further cardiovascular problems, and the patient made a full recovery. The patient's caffeine levels also decreased in accordance with his clinical course (Fig. 2).

\section{Discussion}

Caffeine, 1, 3, 7-trimethylxanthine, is widely sold as a stimulant, anorectic, and diuretic, and it can be conveniently obtained in drug stores. Caffeine is rapidly absorbed with a peak level occurring 0.5 to 2 hours after ingestion. It is metabolized primarily in the liver by the cytochrome $\mathrm{P}_{450} 1 \mathrm{~A} 2$ system, and the elimination half-life is typically 3 to 6 hours in adults. However, this is not the case with caffeine overdoses, and the half-life may be several-fold longer $(2,3)$. A number of cases of severe caffeine intoxication have been reported, and the estimated lethal dose is 10 to $20 \mathrm{~g}$; a possible lethal caffeine concentration is estimated to be $80 \mathrm{mg} /$ L (4).

In our case, the patient ingested approximately $15.6 \mathrm{~g}$ of caffeine, and its peak level was $237 \mathrm{mg} / \mathrm{L}$. The patient also developed sustained ventricular tachycardia despite the conservative treatment. We therefore adapted both hemoperfusion and hemodialysis to remove the caffeine more rapidly. To the best of our knowledge, this is the first report of suc-

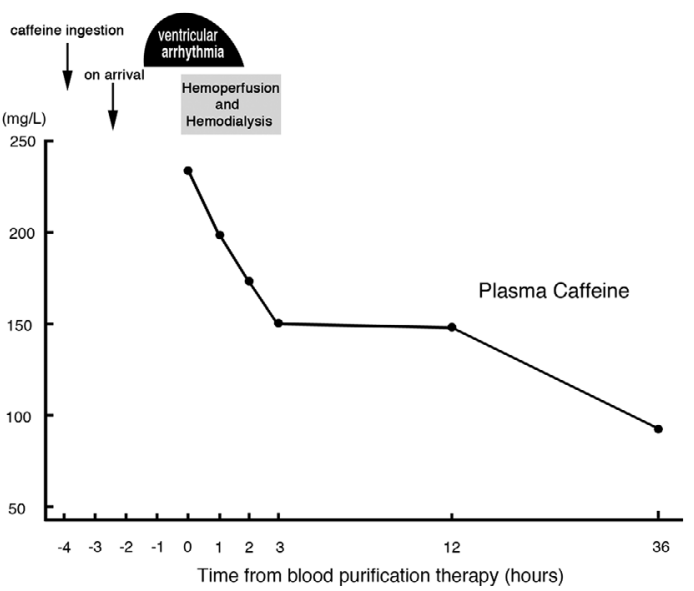

Figure 2. The clinical course of the patient.

cessful treatment by hemoperfusion and hemodialysis for a patient with life-threatening cardiovascular symptoms caused by caffeine intoxication.

Hemoperfusion has previously been carried out to treat patients with caffeine intoxication $(1,5,6)$. More recently, hemodialysis was adopted to remove caffeine in patients with intoxication (7-9). Theoretically, the mean plasma protein binding of caffeine (17\%), the molecular size (molecular weight $194 \mathrm{Da}$ ), and the volume distribution (0.5-0.7 L/ $\mathrm{kg}$ ) make both hemoperfusion and hemodialysis effective methods to remove caffeine $(1,2,7)$. However, the method that more effectively removes caffeine remains unclear, and there is no clear indication of which method should be chosen in cases with potentially lethal ingestion. Thus, we used both methods simultaneously to enhance the caffeine clearance and, as a result, we observed prompt improvement of the patient's ventricular tachycardia (Fig. 1). However, we do not have sufficient data on which method was more effective to remove caffeine in our case. Further studies are necessary to clarify this issue.

In summary, we experienced a case of acute caffeine intoxication with life-threatening cardiac symptoms, and a combination of hemoperfusion and hemodialysis resulted in significant improvement of the patient's symptoms.

The authors state that they have no Conflict of Interest (COI).

\section{References}

1. Dietrich AM, Mortensen ME. Presentation and management of an acute caffeine overdose. Pediatr Emerg Care 6: 296-298, 1990.

2. Kaplan GB, Greenblatt DJ, Ehrenberg BL, et al. Dose-dependent pharmacokinetics and psychomotor effects of caffeine in humans. J Clin Pharmacol 37: 693-703, 1997.

3. Tassaneeyakul W, Birkett DJ, McManus ME, et al. Caffeine metabolism by human hepatic cytochromes P450: contributions of 1A2, 2E1 and 3A isoforms. Biochem Pharmacol 47: 1767-1776, 1994.

4. Leson CL, McGuigan MA, Bryson SM. Caffeine overdose in an adolescent male. J Toxicol Clin Toxicol 26: 407-415, 1988.

5. Zimmerman PM, Pulliam J, Schwengels J, MacDonald SE. Caf- 
feine intoxication: a near fatality. Ann Emerg Med 14: 1227-1229, 1985.

6. Nagesh RV, Murphy KA Jr. Caffeine poisoning treated by hemoperfusion. Am J Kidney Dis 12: 316-318, 1988.

7. Holstege CP, Hunter Y, Baer AB, Savory J, Bruns DE, Boyd JC. Massive caffeine overdose requiring vasopressin infusion and hemodialysis. J Toxicol Clin Toxicol 41: 1003-1007, 2003.

8. Kapur R, Smith MD. Treatment of cardiovascular collapse from caffeine overdose with lidocaine, phenylephrine, and hemodialysis. Am J Emerg Med 27: 253.e3-253.e6, 2009.

9. Fausch K, Uehlinger DE, Jakob S, Pasch A. Haemodialysis in massive caffeine intoxication. Clin Kidney J 5: 150-152, 2012.

(C) 2014 The Japanese Society of Internal Medicine http://www.naika.or.jp/imonline/index.html 